\title{
Determinacy and Taylor's Rule with Different Degrees of Trade Openness in a Semi-New Keynesian Model
}

\author{
Gabriel Karagiannides ${ }^{1}$, Christos Liambas ${ }^{2}$ \\ ${ }^{1}$ SIAM \& IEEE Member, Thessaloniki 54635 , Greece \\ ${ }^{2}$ Dep. of mathematical, physical and computational sciences, Aristotle University of Thessaloniki 54124 , Greece \\ Correspondence: Gabriel Karagiannides, SIAM \& IEEE Member, Thessaloniki 54635, Greece.
}

Received: September 2, 2019

Accepted: September 19, $2019 \quad$ Available online: September 26, 2019

doi:10.11114/aef.v6i6.4503

URL: https://doi.org/10.11114/aef.v6i6.4503

\begin{abstract}
The determinacy question, concerning whether or not there is convergence to a unique equilibrium path, in an explicitly dynamic setting, has been addressed in closed economies but only scantily in an open one. We undertake this task, using a model that leads to a $4^{\text {th }}$-degree characteristic equation which cannot be handled analytically; therefore, we develop a particular algorithm to solve it. We show that the determinacy-consistent specification of Taylor's rule depends, critically, on the greater or lower openness in the trade sector. Greater openness supports a novel specification of Taylor's rule with stronger emphasis on output gaps and weaker emphasis on the price stability than in earlier studies. Under this rule, determinate equilibrium dynamics is shown to be possible. When trade openness decreases significantly, determinacy is still possible, but it is compatible with a far more conventional formulation Taylor's rule where price stability has absolute priority.
\end{abstract}

Keywords: Taylor's rule, trade openness, determinacy, Taylor's principle

\section{JEL Classification: C54, E52}

\section{Short Introductory Remarks}

A crucial theme in macroeconomic dynamics concerns the issue of determinacy, that is, the question of uniqueness or multiplicity of admissible dynamic trajectories. Relevant topical studies have addressed this question in the setting of closed economies. We purport to examine the question of determinacy and how it is affected by Taylor's rule, in the face of varying degrees of trade openness in an economy exhibiting openness in all of its sectors.

The nature of Taylor's work was primarily empirical rather than normative, spawned a large multi-faceted body of literature (see for example, Koenig et al, 2012) and has had profound implications about how monetary policy should be conducted. A remarkable feature of his (1993) celebrated work is that injudiciously designed rules may cause instability and multiple equilibria (indeterminacy/non-uniqueness). For example, in case of an inflationary increase in aggregate demand, the federal funds rate should respond sufficiently enough to enable real interest rates to rise unequivocally, to stifle the incipient inflationary pressure (commonly known as Taylor's principle); otherwise the entire process may evolve in a self-perpetuated way and lead to instability that is a major issue in macroeconomic dynamics. Hence, Taylor's principle and macroeconomic stability/uniqueness (determinacy) were from the beginning, closely intertwined. Although, Taylor's principle has been considered an important guidepost, especially, for monetary policy making, historic periods have existed in which its validity has been questioned, as we shall see in a subsequent discussion.

\section{Review of Antecedent Literature}

The literature on the question of determinacy has increased over the years. An early study was conducted by Clarida et al (2000) who noted the transition from indeterminacy to determinacy since the early eighties (the Volcker-Greenspan era), from the toughening of the anti-inflationary stance that took place. Hirose et al (2017), in revisiting the Great Inflation of the 1970's, conclude, however, that the switch to an anti-inflationary stance was not by itself sufficient to bring inflation down and achieve transition to determinacy, but a number of other factors contributed as well.

Other major studies, in this line of inquiry are Bullard and Mitra (2002), Kiley (2007), Ascari and Ropele (2009), Coibion and Gorodnichenko (2011), Giannoni(2014), Gerko and Sossounov(2015), Arias et al (2017). The former derives analytical conditions for determinacy when expectations are viewed as a learning process, and is still considered 
as a major reference work in this area. Their stability condition derived under a contemporaneous data policy rule (besides forward-looking and back-ward looking rules) has been called the generalized Taylor's principle (Woodford (2003, ch.4; Ascari and Ropele,2009) and pertains to the long run. In Bullard and Mitra (2007) it is shown that the presence or not of inertia in the policy rule matters critically for the issue of determinacy; its presence promotes equilibrium determinacy. Accordingly, it has emerged as an important factor for the matter at hand, as attested by the studies examined in the following discussion.

Subsequent studies sought to re-examine Taylor's principle regarding determinacy, from a variety of perspectives where the inflation rate features prominently and, in particular, exhibits trend in its behavior. In their analysis of a New Keynesian model with capital accumulation and possible price indexation, Ascari and Ropele (2009) showed that trend inflation expands the indeterminacy region in the parameter space. Taylor's principle breaks down and the generalized principle emerges necessary but not sufficient to generate determinacy. For a certain level of trend inflation in the zero indexation case, response to output gaps is not inimical to determinacy. They also find that an interest rate rule with inertia renders the Taylor principle simply of minor importance and it is the output gap response that is of actual relevance. Furthermore, Coibion and Gorodnichenko (op.cit.), in their empirical investigation of the Great Moderation era, sought to critically re-examine the determinacy question and noted that determinacy may exist without necessarily Taylor's principle be satisfied; the switch to determinacy after the Volcker disinflation occurred also because of the decline of trend inflation and the change in the Fed's general policy stance. The model of Gerko and Sossounov(2015) combines trend inflation with capital accumulation; they find that indeterminacy exists if the target rate of inflation exceeds two percent. Notably, they find support for a monetary rule that reacts to output fluctuations but to a measured extent. More recently, Arias et al (2017), examine the period of Great Moderation, in a New Keynesian model with capital accumulation, and conclude that determinacy exists when the target rate of inflation is in the range of two to four percent conditional on the monetary rule being estimated from their model.

Ambler and Lam (2015), compared inflation targeting (IT) with price level targeting (PLT), and concluded that for the parameter space examined, indeterminacy does not arise under PLT (contrary to the case of IT). Earlier, in a broadly similar vein, Dittmar and Gavin (2005), in a RBC model with money and capital accumulation, had shown that determinacy obtains when the policy coefficient on the price level belongs to the interval $(0,2)$ with a zero policy coefficient on inflation. Interestingly enough, Coibion and Gorodnichenko(op.cit) showed that pursuing strict PLT is equivalent to following a highly inertial interest rate rule that ensures determinacy either for zero or for positive trend inflation. In a parallel spirit, Giannoni(2014) in a purely New Keynesian closed economy model shows that rule with a PLT component implies inertia and determinate equilibrium, when the policy coefficients are positive, rendering the Taylor principle irrelevant. Though not addressing the determinacy issue, worthy of mention, is the study by Dib et al (2013) in that they show that PLT relative to CPI inflation targeting, reduces welfare costs by alleviating the costs of financial shocks and frictions associated with uncertainty surrounding nominal debt contracts in a New Keynesian model of Canada.

Crucial exceptions to the above body of works, are the studies of De Fiore and Liu (2005), Lliosa and Tuesta(2008). The former derives rigorous conditions that the parameters concerning the degree of trade openness and strict inflation rules (passive or active) must satisfy, in order for equilibrium determinacy to exist. The economy envisaged in their work is primarily one of pure exchange. When this assumption is relaxed, labor is the sole factor input entering the production process. In the present work, however, the possibility of an imported factor input is not ruled out, which is more appropriate for the case of a small open economy that is our main focus. Lliosa and Tuesta (op. cit.) show how the Bullard-Mitra determinacy and learnability conditions are modified in the case of a small open economy; like the previous study, they abstract from the presence of a foreign input and although they consider various rules, the one with a PLT component is not among them.

Here, we concentrate on probing the determinacy properties of Taylor's rule that affords, through a particular approach, clear insight regarding the role trade openness. For the reason mentioned below, less emphasis shall be given on the formal analytical stability conditions and more on the calibrated data analysis based on plausible examples of economies. In contrast to earlier simpler models, the one used in this study is an extended three-equation framework in which the LaSalle stability conditions turn out practically inapplicable. This necessitates the use of a numerical approach which, from methodology point of view, shall prove particularly illuminating for an issue that has been only scantily researched and there is scope for further probing. Furthermore, in the light of earlier findings, instead of inflation targeting we choose to focus on a Taylor monetary rule, specified in terms of stabilizing price level deviations and output gaps.

The main finding of this paper may be stated as follows. Convergence to a unique equilibrium is shown to be attainable in open economies of different size, conditional on the proper specification of the policy rule. Further, it is shown through numerical analysis of alternative cases that the design of determinacy-consistent Taylor's rule is critically 
linked to the degree of trade openness. In particular for a higher degree of trade openness, the role of output gaps gains in significance with the price level acquiring only a slim priority in significance. For a lower degree of trade openness, however, far more conventional results of prior studies are replicated, in which price stability takes absolute precedence. The importance of the degree of trade openness is sufficiently illustrated for the issue determinacy and how Taylor rules should be designed.

In the light of earlier findings, when the policy rule has a PLT component, as in our case, Taylor's principle is reduced to a state of irrelevance. Moreover, the integration of an exchange rate channel in the supply sector has mainly quantitative rather than qualitative effects. Finally, the question of the optimal monetary policy in an open economy is briefly addressed.

The structural blocks of the model, its final matrix form, technical issues involved and the annotated results are discussed in the following sections.

\section{The Model}

\subsection{The Aggregate Demand Sector}

Our general findings are derived through a model which is an 'amalgam' of diverse elements combined in an eclectic manner. It is eclectic because while the households sector is assumed to make consumption decisions according to the New Keynesian paradigm, the wage-price sector functions in a way that diverges from this paradigm.

The following open economy output equation together with its structural foundation elements, serve our purposes well as an analytical vehicle. They are following the basic structure of Clarida et al (2001), Gali (2008, ch. 7),Lim and McNelis (2008, ch.2) and, especially, Guender (2011), that is common in this type of models:

$$
\begin{aligned}
Y_{t}=- & \Phi_{1}\left\{r_{t}-E_{t}\left[\theta P_{t+1}+(1-\theta)\left(\mathcal{E}_{t+1}+P_{t+1}^{f}\right)-\left(\theta P_{t}+(1-\theta)\left(\mathcal{E}_{t}+P_{t}^{f}\right)\right)\right]\right\}+\Phi_{2}\left[\mathcal{E}_{t}+P_{t}^{f}-P_{t}-E_{t}\left(\mathcal{E}_{t+1}+\right.\right. \\
& \left.\left.P_{t+1}^{f}-P_{t+1}\right)\right]+\Phi_{3}\left(Y_{t}^{f}-E_{t} Y_{t+1}^{f}\right)+E_{t} Y_{t+1}+\omega_{t}
\end{aligned}
$$

where: $C P I_{t}=\Pi_{t}=\left(\theta P_{t}+(1-\theta)\left(\mathcal{E}_{t}+P_{t}^{f}\right)\right)$ is the domestic Consumer Price Index

$(1-\theta)=$ a measure of the degree of trade openness as in earlier studies

$Y_{t}=$ output, $P_{t}=$ domestic price level, $r_{t}=$ nominal interest rate, $E_{t}=$ domestic currency units per unit of foreign currency, $P_{t}^{f}=$ foreign goods price index, $Y_{t}^{f}=$ foreign output; $\mathcal{E}_{t}+P_{t}^{f}-P_{t}=$ the real exchange rate; $\omega_{t}$ is a preference shock described by a white noise process. $\Phi_{i,} i=1,2,3$ are composite parameters. Expectations are supposed to be rational, and variables (except for interest rates) are typically in logarithms. The steady state rate of inflation is constant, that in full equilibrium could be taken as zero.

The following text provides a basic description. Equation (3.1.1) describes the home output equation (which equals aggregate consumption, $C_{t}$ ), in a small open dynamic economy. On the output side, output consists of home goods internally consumed $\left(C_{t}^{d}\right)$, and home goods exported abroad $\left(C_{t}^{d f}\right)$. The aggregate consumption $\left(C_{t}\right)$ is divided between home goods consumed by domestic households $\left(C_{t}^{d}\right)$, and imported consumption goods bought by domestic households $\left(C_{t}^{f}\right)$.

Optimal intra-period share of aggregate consumption spent on domestic goods is described by the following standard condition:

$$
C_{t}^{d}=\ln (\theta)-\eta\left[\left(P_{t}-C P I_{t}\right)\right]+C_{t}
$$

Setting $\eta=1$, substituting for $C P I$ and re-arranging, the previous equation takes the form:

$$
C_{t}^{d}=(1-\theta)\left(E_{t}+P_{t}^{f}-P_{t}\right)+\ln (\theta)+C_{t}
$$

Leading one period forward and taking expectations results in:

$$
E_{t} C_{t+1}^{d}=(1-\theta) E_{t}\left(E_{t+1}+P_{t+1}^{f}-P_{t+1}\right)+\ln (\theta)+E_{t}\left[C_{t+1}\right]
$$

Subtracting by sides, results in: 


$$
C_{t}^{d}-E_{t} C_{t+1}^{d}=(1-\theta)\left[\left(\mathcal{E}_{t}+P_{t}^{f}-P_{t}\right)-E_{t}\left(E_{t+1}+P_{t+1}^{f}-P_{t+1}\right)\right]+\left(C_{t}-E_{t}\left[C_{t+1}\right]\right)
$$

The aggregate consumption $C_{t}$ involves standard inter-temporal utility maximization of consumption over time (described in Appendix A.1), subject to an inter-temporal budget constraint involving aggregate consumption plus one-period real bonds (i.e. deflated by $C P I=\Pi$ ) along with their gross, risk-less interest returns as they change from one time period to the next. Lagrangian intertemporal optimization which takes prices as given and maximizes with respect to quantities (consumption and bonds), leads to the following well-known Euler condition for consumption:

$$
C_{t}=\operatorname{constant}(=-\rho \ln \beta)+E_{t}\left[C_{t+1}\right]-\rho\left(r_{t}-E_{t} \pi_{t+1}^{C P I}\right)+\rho v_{t}
$$

where $\rho$ is the intertemporal substitution elasticity and $\pi_{t}^{C P I}$ is CPI inflation rate at $t$.

Substituting (3.1.3) into (3.1.2d) provides us the first structural foundation component. The second component begins with acknowledging that aggregate output, after log-linearization, consists of home consumption and domestic exports (relative to their means):

$$
Y_{t}-\bar{Y}=(\theta)\left(C_{t}^{d} \overline{-C^{d}}\right)+(1-\theta)\left(C_{t}^{d f} \overline{-C^{d f}}\right)
$$

Leading one period ahead and taking expectations leads to:

$$
\left(E_{t} Y_{t+1}-\bar{Y}\right)=(\theta)\left(E_{t} C_{t+1}^{d} \overline{-C^{d}}\right)+(1-\theta)\left(E_{t} C_{t+1}^{d f}-\overline{C^{d f}}\right)
$$

Denoting with small-case letters the variables relative to their steady state and subtracting by sides, results in:

$$
y_{t}-E_{t} y_{t+1}=(\theta)\left(c_{t}^{d}-E_{t} c_{t+1}^{d}\right)+(1-\theta)\left(c_{t}^{d f}-E_{t} c_{t+1}^{d f}\right)
$$

Equation (3.1.5) may be said to lie at the core of the present frame and plays a key role in the construction of the derived output equation. Exports (relative to their forward expectation) are assumed to depend on the real exchange rate and foreign output(relative to their respective forward expectation). Using the exports equation as described above and equation (3.1.2d), both in deviatons form, plugging them into (3.1.5) and re-arranging, we obtain equation (3.1.1 $\alpha$ ), after re-prameterizing, that is the counterpart of (3.1.1) with the variables expressed as deviations relative to their means(including the nominal interest rate).

Higher-ceteris paribus- interest rates affect not only aggregate demand but also the supply sector. Through the channel of intertemporal substitution (output squeezing) and through attracting foreign funds that cause depreciation in $\mathcal{E}_{t}$ thus depressing demand and expanding supply as it turns out. The net effect on $Y_{t}$ and $P_{t}$ is likely negative calling for a policy-induced reduction in interest rates that sets off the equilibrating process. All these signify the importance of the trade sector's openness that features prominently throughout the analysis.

\subsection{The Home Pricing Sector}

The pricing scheme employed generally departs from earlier New Keynesian literature and in some respects, it envisages a different frame incorporating features that could be described as pragmatic. The starting point of our pricing scheme is, unlike earlier studies, the Rotemberg (1982) optimizing framework, in which monopolistically competitive firms face intratemporal and intertemporal costs of adjustment when changing their price. Recent macro-data examined by Richter and Throckmorton (2016), justifies the shift in favour of such a scheme; hence algebraically:

$$
\begin{gathered}
\min (L S)=E_{t} \sum_{i=0}^{\infty} \xi^{i}\left[\kappa\left(P_{t+i}-P_{t+i-1}\right)^{2}+\mu\left(P_{t+i}-P_{t+i}^{*}\right)^{2}\right] \kappa, \mu>0 \\
P_{t}=\alpha_{1} P_{t-1}+\alpha_{2} P_{t}^{*}+\alpha_{3} E_{t} P_{t+1} \\
\alpha_{1}+\alpha_{2}+\alpha_{3}=1, \alpha_{3}=\xi \alpha_{1} \text { where } \xi=\text { discount factor=0.99 } \\
\alpha_{1}=\frac{\kappa}{\kappa+\mu+\xi \kappa}, \alpha_{2}=\frac{\mu}{\kappa+\mu+\xi \kappa}, \alpha_{3}=\frac{\xi \kappa}{\kappa+\mu+\xi \kappa}
\end{gathered}
$$

Equation (3.2.2) together with the set of relations (3.2.3), obtained after optimizing (3.2.1) with respect to $P_{t}$ and re-parameterising, describe a scheme comprising: a) a predetermined price variable, b) a forward -looking price term and c) an equilibrium price term, $P_{t}^{*}$, that would have prevailed if there were price flexibility (with $\left.\mu>0, \kappa=0\right)$. 
Our next task is to derive an expression for $P_{t}^{*}$, from a price flexible equilibrium frame and thus close essentially the pricing scheme. $P_{t}^{*}$ is given in terms of a mark-up, $\ln \left[\frac{\epsilon}{\epsilon-1}\right],(\in>1$, defined as demand elasticitity) augmented by the marginal cost, $(M C)_{t}$, that is:

$$
P_{t}^{*}=\ln \left[\frac{\epsilon}{\epsilon-1}\right]+(M C)_{t}
$$

The (total) mark-up ( $\ln \left[\frac{\epsilon}{\epsilon-1}\right]$ ) is assumed to consist of a constant and a variable component. The variable component of firms mark-up is assumed to vary inversely with output fluctuations $\left(Y_{t}-\bar{Y}\right)$; though evidence is not unanimous, the tentative consensus is that, in general, firms mark-ups tend to be countercyclical.

We further assume that the nominal wage rate (component of the marginal cost) is set according to a wage-setting scheme that takes into account institutionalized factors. Indexation schemes have been used in various Eurozone countries (ECB Monthly Bulletin, Prices and Costs, May, 2008); the cases of Belgium and Luxembourg are very characteristic examples.

Because the labor market is highly differentiated and fragmented, we assume that it consists of two segments. Accordingly, the real wage is set according to two schemes:

$$
\begin{array}{cc}
\left(W_{t}\right)^{\text {inflex }}=\tau_{1}\left(q_{1}^{N}\right)_{t}+\Pi_{t} & 0<\tau_{1} \leq 1 \\
\left(W_{t}\right)^{\text {flex }}=\tau_{2}\left(q_{2}^{N}\right)_{t}+\Pi_{t}+\zeta_{1}\left(Y_{t}-\bar{Y}\right) & 0<\tau_{2}<1 \\
W_{t}=\psi W^{\text {inflex }}+(1-\psi) W^{\text {flex }} &
\end{array}
$$

$q_{i}^{N}(i=1,2)$ is labour productivity in each segment assumed to be pro-cyclical despite recent shifts in its behavioral pattern; $\tau_{1}$ is close to unity (or may equal it) while $\tau_{2}$ is below unity.

The first segment is characterized by real wage rigidity (especially downwards) that is well documented particularly in cases dominated by powerful trade unions that are disinclined to accept real wage cuts. The presence of collective bargaining and employment protection legislation are further contributing factors. These are relevant to the scheme (3.2.4b). In the other segment, the labor force contains newly hired workers who are non-union members and includes less skilled workers who prefer greater employment stability, trading it off with greater real wage flexibility; thus, scheme (3.2.4c) becomes relevant. The term $\left(Y_{t}-\bar{Y}\right)$ approximates conditions in the labor market and the economy in general. In this case, there is no collective bargaining but rather individual firm-worker agreements. Note that unlike the former, the latter scheme effectively implies less than full indexation if $Y_{t}<\bar{Y}$. Bauer et al (2007), in their analysis, conclude that real wage rigidity remains important though its importance is declining over time.

Next, we turn to the total cost equation consisting of labor cost and the foreign input cost. Both inputs enter a Cobb-Douglas production function:

$$
Y_{t}=\ln \Theta_{0}+\delta_{1} N_{t}+\delta_{2} Z_{t}
$$

where: $N_{t}=$ labour input and $Z_{t}=$ foreign input imported from abroad; $\Theta_{0}=1$ for simplicity.

Marginal cost obtains from total cost and after performing log-linearization, it has the following form:

$$
(M C)_{t}=z_{0}+z_{1}\left[W_{t}+N_{t}-Y_{t}-\ln \left(\delta_{1}\right)\right]+z_{2}\left[\mathcal{E}_{t}+\left(P_{t}^{z f}\right)+Z_{t}-Y_{t}-\ln \left(\delta_{2}\right)\right]
$$

$\left(z_{0}\right.$ is a constant including the steady state means of variables, $z_{1}+z_{2}=1$ )

According to our hypothesis, the wage rate is set according to the schemes described earlier and firms determine the demand. The demand equations for the two inputs, $N_{t}$ and $Z_{t}$, are determined by firms when price flexibility is prevalent: 


$$
\begin{gathered}
N_{t}=-\left(\left[1-\delta_{2}\right] /\left[1-\delta_{2}-\delta_{1}\right]\right)\left(W_{t}-P_{t}^{*}\right)-\left(\left[\frac{\delta_{2}}{\left[1-\delta_{2}\right.}-\delta_{1}\right]\right)\left(\left(\mathcal{E}_{t}+P_{t}^{Z f}\right)-P_{t}^{*}\right)+ \\
{\left[1-\delta_{2}-\delta_{1}\right]^{-1} \ln \left[\frac{\epsilon-1}{\epsilon}\right]+\frac{\left[\left(1-\delta_{2}\right) \ln \left(\delta_{1}\right)+\delta_{2} \ln \left(\delta_{2}\right)\right]}{1-\delta_{1}-\delta_{2}}} \\
Z_{t}=-\left(\delta_{1} /\left[1-\delta_{2}-\delta_{1}\right]\right)\left(W_{t}-P_{t}^{*}\right)-\left(\left[1-\delta_{1}\right] /\left[1-\delta_{2}-\delta_{1}\right]\right)\left(\left(\mathcal{E}_{t}+P_{t}^{z f}\right)-P_{t}^{*}\right)+ \\
{\left[1-\delta_{2}-\delta_{1}\right]^{-1} \ln \left[\frac{\epsilon-1}{\epsilon}\right]+\left[\frac{\delta_{1} \ln \left(\delta_{1}\right)+\left(1-\delta_{1}\right) \ln \left(\delta_{2}\right)}{1-\delta_{1}-\delta_{2}}\right]}
\end{gathered}
$$

Note that when firms function in imperfectly competitive circumstances in, both, the product and the labor market, the level of employment is lower than it would be under perfect competition, an employment outcome that has been described by Joan Robinson (1933), the great Cambridge economist, as " monopolistic exploitation".

Substituting next (3.2.5b) and (3.2.5c) into the marginal cost equation, (3.2.5a) and using the (3.2.4 b,c,d) enable us to obtain, after extensive re-arrangements and exploiting (3.2.4a), the equation of $P_{t}^{*}$, after taking deviations and re parameterizing:

$$
P_{t}^{*}-\bar{P}=\gamma_{1}\left(Y_{t}-\bar{Y}\right)+\gamma_{2}\left(\mathcal{E}_{t}-\overline{\mathcal{E}}\right)+\gamma_{3}\left(P_{t}^{z f}-\overline{P_{t}^{z f}}\right)+\gamma_{4}\left(P_{t}^{f}-\overline{P_{t}^{f}}\right)
$$

where: $\gamma_{1}, \gamma_{2}, \gamma_{3}, \gamma_{4}$ are composite parameters,$P_{t}^{z f}=$ foreign currency price of the foreign input and $P_{t}^{f}=$ foreign goods price index; this completes the description of the wage-price sector structure.

\subsection{The International Financial Sector}

In complete financial markets, international investors who are risk-neutral generate, through arbitrage, uncovered interest rate parity (UIP) taking the simple form:

$$
r_{t}=r_{t}^{f}+E_{t} E_{t+1}-E_{t}
$$

where $r_{t}^{f} i$ s the rate of interest prevailing abroad, and $E$ is the familiar expectations symbol.

\subsection{The Home Monetary Policy Reaction Function}

We close the model with a contemporaneous linear feedback rule that is a variation of Taylor's empirically established policy instrument rule and serves our particular purposes ( assumed to be known by the public):

$$
r_{t}=\bar{r}+\bar{\pi}+\Phi_{P}\left(P_{t}-\bar{P}\right)+\Phi_{Y}\left(Y_{t}-\bar{Y}\right)
$$

where $\bar{r}$ is the natural rate of interest, and $\bar{\pi}$ is the steady inflation rate that may be constant or in full equilibrium, zero. Woodford (2003, ch.2) calls this rule Wicksellian.

\section{The Entire Model in Final Matrix Form}

Some clarifying remarks are necessary first. All foreign variables, including foreign output (except the demand for foreign input, $Z_{t}$ ) are chosen not to be modeled explicitly, and assume to follow a white noise pattern as in Guender (2011). This assumption has been made with a view to concentrate on the present system that turns out complex enough. We denote with a hat all variables relative to their steady state and make more compact relevant notation. Focusing on the equations (3.1.1 $\alpha$ ) and (3.2.2), (3.3.1) (the latter in deviations form), substituting appropriately equations (3.4.1) and (3.2.6) in them, and collecting forward expectations on the left-hand side, there obtains the canonical model:

$$
\begin{gathered}
C_{10}\left[\begin{array}{lll}
\widehat{Y}_{t+1, t}^{e} & \hat{P}_{t+1, t}^{e} & \widehat{\mathbb{E}}_{t+1, t}^{e}
\end{array}\right]^{\prime}=C_{20}\left[\begin{array}{lll}
\hat{Y}_{t} & \hat{P}_{t} & \widehat{\mathbb{E}}_{t}
\end{array}\right]^{\prime}+C_{30}\left[\begin{array}{lll}
\hat{Y}_{t-1} & \hat{P}_{t-1} & \widehat{\mathbb{E}}_{t-1}
\end{array}\right]^{\prime} \\
\text { where } C_{10}, C_{20}, C_{30} \text { are given in the Appendix A.2. }
\end{gathered}
$$

We pre-multiply by $C_{10}^{-1}$, to obtain the following canonical (homogenous) form of the model: 


$$
\left[\begin{array}{llll}
100 & 010 & 001
\end{array}\right]^{\prime}\left[\begin{array}{lll}
\hat{Y}_{t+1, t}^{e} & \hat{P}_{t+1, t}^{e} & \widehat{\mathscr{E}}_{t+1, t}^{e}
\end{array}\right]^{\prime}-C_{10}^{-1} C_{20}\left[\begin{array}{lll}
\widehat{Y}_{t} & \widehat{P}_{t} \widehat{\mathscr{E}}_{t}
\end{array}\right]^{\prime}-C_{10}^{-1} C_{30}\left[\widehat{Y}_{t-1} \widehat{P}_{t-1} \widehat{\mathscr{E}}_{t-1}\right]^{\prime}=0
$$

Let $M_{t}=\left[\begin{array}{lll}\widehat{Y}_{t} & \widehat{P}_{t} \widehat{\mathcal{E}}_{t}\end{array}\right]^{\prime}$, then the homogenous solution is $M_{t}=\sum_{0}^{6} n_{i} m_{0} \lambda_{i}^{t}$ where $n_{i}$ is the $i$ eigen vector and $\lambda_{i}$ the $i$ eigen value obtained, from a 6th-degree polynomial equation having common factor $\lambda^{2}$. Factoring it out, we derive a $4^{\text {th }}$-degree polynomial equation; let $A(\lambda)$ be the $4^{\text {th }}$-degree polynomial:

$$
\lambda^{4}+A_{3} \lambda^{3}+A_{2} \lambda^{2}+A_{2} \lambda^{2}+A_{0}
$$

LaSalle (1986) provides the conditions by which -if and only if they hold- stability of $A(\lambda)$ exists. The conditions are as follows:

$$
\begin{gathered}
\left|A_{2}\left(1-A_{0}\right)+A_{0}\left(1-A_{0}^{2}\right)+A_{3}\left(A_{0} A_{3}-A_{3} A_{1}\right)\right|<A_{0} A_{2}\left(1-A_{0}\right)+\left(1-A_{0}^{2}\right)+A_{1}\left(A_{0} A_{3}-A_{1}\right) \\
\left(\text { b) }\left|A_{0}\right|<1, \quad \text { (c) }\left|A_{1}+A_{3}\right|<1+A_{2}+A_{0}\right.
\end{gathered}
$$

These conditions, howerver, turn out to consist of overly long and extremely intractable expressions.

Now, given how our model (4.1) has been stacked, we appeal to the Blanchard-Khan (1980) criterion, as the basis of our analysis as in most, if not all, of earlier literature. In our case, three characteristic roots/eigen values must be outside the unit circle, because a triplet of forward-looking variables exists (on the left-hand side); the resulting equilibrium is of a saddle point nature.

To gain a more concrete perspective let us ignore for the time being the backward-looking term, in which case our system could be simply written :

$$
E_{t} M_{t+1}=J M_{t} \quad \text { (4.4a) } \quad \text { or alternatively: } \quad M_{t}=J^{-1} E_{t} M_{t+1}
$$

with $M_{t}$ being a $3 \times 1$ vector defined as before and $J$ being $3 \times 3$ (non - singular) matrix.

If the eigen values of $J$ are outside the unit circle then the eigen values of $J^{-1}$ (being the inverses of the eigen values of $J$ ) are inside the unit circle, rendering thus the process described in (4.4b) stable (this applies and vice versa in the sense that if $4.4 \mathrm{~b}$ is unstable then $4.4 \mathrm{a}$ is stable). Hence, the way in which a system of forward-looking variables has been specifically formulated matters critically for its stability behavior. We use formulation (4.4a) whereas Bullard and Mitra (2002) use formulation (4.4b). One may choose either of them provided in each case the stability conditions are correctly specified.

The core of the preceding may be found elsewhere (Farmer, 1999;Woodford,2003) but it is useful to reiterate and clarify them prior to proceeding to the examination of the issue through a different approach, namely the algorithmic one, a theme which we now discuss.

\section{Results and Discussion}

We begin by stipulating that policy parameters $\Phi_{P}$ and $\Phi_{Y}$ belong to an interval, broadly in line with topical literature (e.g. Dittmar and Gavin, 2005; Ambler and Lam, 2015). To derive the four characteristic roots, satisfying the Blanchard-Khan theorem, we make use of the following set of calibration values, after inspecting carefully other sets, as well:

$$
\begin{gathered}
\Phi_{1}=0.30, \Phi_{2}=0.25, \gamma_{1}=0.05, \gamma_{2}=0.1, \alpha_{1}=0.2513, \alpha_{2}=0.5, \alpha_{3}=0.2487 \\
\left(\Phi_{P} \in(0,2)\right),\left(\Phi_{Y} \in(0,2)\right)
\end{gathered}
$$

Some of these values have been adopted from Froyen and Guender (2007, p.268); relevant topical literature has, also provided useful guidance. The initial value of $\theta$ has been taken from World Bank Statistics, so that it is broadly representative (until recently), of a group of industrial small open economies, similar to Portugal and Austria (both Euro-zone members). On the whole, our entire parameterization has been carefully chosen to be sufficiently representative of a broader range of countries. 
a) Of particular and critical significance, is the value of $\theta$ that determines the degree of trade openness $(1-\theta)$. We set initially $\theta=0.6$ in which case $1-\theta=0.4$. As we shall see, we experiment with two values of this parameter in order to have a broader perspective of the forthcoming results (of the two cases we examine, we call this, case A). A clarifying note first: by construction, $\Phi_{1}$ is equal to $\theta \rho$ with $\rho=0.5$ in the case of Austria (Liu and Sercu, 2009). Another auxiliary assumption that has implicitly been made is that the share of imports in foreign consumption is quite low.

The proposed algorithm is a device specifically developed to perform a grid search using 0.1 as a step in deriving the values of $\Phi_{Y}$ and $\Phi_{P}$ for which determinacy turns out to exist.

The outcome is a map of correspondence between policy coefficients of the Taylor rule and determinacy equilibrium outcomes; this map enlightens the question of determinacy, regarding the nature of macroeconomic dynamics in the open economy. This approach does not distinguish between determinacy/indeterminacy regions but rather affords a locus of equilibrium determinacy points.

We observe a more equivocal relationship between the policy parameter values than before that has profound implications for the conduct of monetary policy. Thus, it is shown through our approach, that determinacy may exist without the satisfaction of Taylor's principle that is consonant with the point made in the empirical analysis of the U.S economy by Coibion and Gorodnichenko (2011) and others. To broaden our perspective, we should mention that in contrast to these results, De Fiore and Liu (2005), in the sticky price version of their model (using a contemporaneous (active) inflation rule), found that Taylor's principle must necessarily hold for determinacy regardless of the degree of trade openness.

Further, our algorithmic device has produced an interesting dissection in the range of findings concerning the properties of Taylor's rule. More specifically, we find that at the lower end of the range of our findings, $\Phi_{P}$ (reflecting price stability) is lower than $\Phi_{Y}$ (reflecting output stability) that is an uncustomary finding, whereas at the other (higher) end of the derived range, we obtain the far more typical result where $\Phi_{P}>\Phi_{Y}$ as in most studies. In contrast, -and this is equally uncustomary finding-the value of $\Phi_{Y}$ has been found to be definitely higher than in most other determinacy studies, thus turning on their head previous results that generally called for a small response to output gaps. For example, Ambler and Lam (2015) in their closed economy set-up, find that the output stability coefficient is in the range between zero and one that is representative of earlier literature. A notable exception, is Coibion and Gorodnichenko(op. cit.) who favor a robust response to output gaps that makes the generalized Taylor's principle be satisfied provided that there is zero or low trend inflation. Earlier, Williams (1999) had shown, under rational expectations, that a flexible PLT(with a non-negligible output coefficient) converges to the optimal policy rule, in the output-inflation variance trade-off frontier, if $\varphi$ is equal or greater than 0.5 where $\varphi$ denotes the weight attached to output stabilization. His results regarding the optimal rule prove robust to model uncertainty. Moreover, there is evidence by Dib et al (1013) according to which they report, from a welfare point of view, a higher output coefficient under a PLT rule than the one under IT rule.

In our open economy, it is possible that a higher $\Phi_{Y}$ may substitute for a lower $\Phi_{P}$ value so that some balance may be restored that contributes to equilibrium determinacy. Priority lies with price stability (only at the upper end of the values range), but the novelty is that output gaps should also be far more seriously taken into account than previously, at least when PLT and not IT forms part of the rule. This key finding and the rest of the results modify drastically our conventional perception of Taylor's equation (at least, as regards, case A). These are portrayed in the following findings:

$$
\left(0<\Phi_{P} \leq 1.9\right],\left(0<\Phi_{Y} \leq 1.7\right]
$$

The findings of Ball (1999), favor the upgraded role of output in the sense that there is an improvement (relative to the closed economy) in the trade-off variability between output and inflation without, however, addressing the determinacy issue, using a different model that emphasizes lagged behavior of the variables involved. Moreover, Froyen and 
Guender (2007) and Guender (2011) found drastic implications (albeit from a different perspective), depending on the presence or not, of an exchange rate channel in the wage-price sector.

Motivated by their finding, we repeat our analysis by setting the $\gamma_{2}$ parameter equal to zero and examine the implications for the determinacy issue, when the exchange rate impacts only the trade sector. The deeper essence of the foregoing results does not change much. The whole picture changes only quantitatively; the finding about the significance of output gaps is still robust to this change in specification. Intuitively, it is possible that the significance of output gaps may reflect actions taken by the authorities, to attenuate exchange rate volatility to avoid a serious impact on output volatility.

b) Because the question of openness lies at the centre of our discussion, examining the implications of a smaller degree of trade openness is also critical, by setting $\theta=0.85$ implying a degree of trade openness, $1-\theta=0.15$, approximately one-third of its initial value; this pertains to the case of the United States economy (this is our case B).The value of $\rho$ is set, in this case, equal to 0.35 that is well within the range of suggested values (Kilponen et al, 2013); also, in this case, the share of imports in foreign consumption is assumed to be high(unlike the previous case). The previous results change drastically, acquiring a far more conventional form. In particular, we obtain:

$$
\left(0<\Phi_{P} \leq 1.8\right],\left(0<\Phi_{Y} \leq 0.8\right]
$$

with the majority of values converging approximately 1.5 in the former case, and 0.55 in the latter case, as in traditional literature, which mostly pertains to the closed economy setting. In the present case, it always obtains that $\Phi_{P}>$ $\Phi_{Y}$. As noted earlier, this does not hold in case A, where both goals (price and output stability) are significant, implying from a normative point of view, that underrating the significance of output gaps is in this case, clearly not warranted. Thus, from determinacy point of view, the difference between case A and B is striking and may be solely ascribed to the different degree of trade openness.

Taylor's principle has been a controversial and equivocal issue. If concentrated on the pr ice stability coefficient, we may simply observe that it is often smaller than unity regarding case A. As noted previously, determinacy may exist without the requirement of Taylor's principle. Case B is different, in which $\Phi_{P}>$ 1, typically holds. According to Giannoni (op.cit.), however, the preceding are of no importance for Taylor's principle as long as $\Phi_{P}$ and $\Phi_{Y}$ are positive if the rule has a PLT component as in the present case.

Overall, the results of our particular model show that determinacy is feasible, contingent on the proper specification of Taylor's rule. Moreover, the analyses of experiments based on cases A and B, reveal sharp differences depending on the degree trade openness; the latter is shown, by example, to be a crucial factor in the design of determinacy-consistent Taylor rules.

\section{References}

Ambler, S., \& Lam, J. P.(2015). Inflation Targeting, Price Level Targeting, the Zero Lower Bound and Indeterminacy. Working Paper 15-03, Rimini Centre for Economic Analysis.

Arias, J. E., Ascari, G., Branzoli, N., \& Castelnuovo, E. (2017). Positive Trend Inflation and Determinacy in a Medium-Sized New Keynesian Model”, Working Paper 17-16, Federal Reserve Bank of Philadelphia. https://doi.org/10.21799/frbp.wp.2017.16

Ascari, G., \& Ropele, T. (2009). Trend Inflation, Taylor's Principle and Indeterminacy. Journal of Money, Credit and Banking, 41(8), 1557-1584. https://doi.org/10.1111/j.1538-4616.2009.00272.x

Ball, L. (1999). Policy Rules for Open Economies in: Monetary Policy Rules, ed., by John B. Taylor, National Bureau of Economic Research Conference Report. https://doi.org/10.3386/w6760

Bauer, T., Bonin, H., Goette, L., \& Sunde, U. (2007). Real and Nominal Wage Rigidities and the Rate of Inflation. Economic Journal, 117(524), 508-529. https://doi.org/10.1111/j.1468-0297.2007.02094.x

Blanchard, O. J., \& Khan, C. M. (1980). The Solution of Linear Difference Models under Rational Expectations. 
Econometrica, 48(5), 1305-1311. https://doi.org/10.2307/1912186

Bullard, J., \& Mitra, K.(2002). Learning about Monetary Policy Rules. Journal of Monetary Economics, 49(6), 1105-1129.

_ (2007). Determinacy, Learnability and Monetary Policy Inertia. Journal of Money,Credit and Banking. 39(5), 1177-1212.

Clarida, R., Gali, J., \& Gertler, M. (2000). Monetary Policy Rules and Macroeconomic Stability: Evidence and Some Theory. Quarterly Journal of Economics, 115(1), 147-180. https://doi.org/10.1162/003355300554692

_ (2001). Optimal Monetary Policy in Open versus Closed Economies: An Integrated Approach. AEA Papers and Proceedings, pp. 248-252.

Coibion, O., \& Gorodnichenko, Y. (2011). Monetary Policy, Trend Inflation and the Great Moderation: An Alternative Interpretation. American Economic Review, 101(1), 341-370. https://doi.org/10.1257/aer.101.1.341

De Fiore, F., \& Liu, Z. (2005). Openness and Equilibrium Determinacy under Interest Rate Rules. Journal of Economic Dynamics and Control, 29(7), 1165-1192. https://doi.org/10.1016/j.jedc.2004.06.001

Dib, A., Mendecino, C., \& Zhang, Y. (2013). Price Level Targeting in a Small Open conomy with Financial Frictions: A Welfare Analysis. Economic Modelling, 30(c), 941-953. https://doi.org/10.1016/j.econmod.2012.09.038

Dittmar, R., \& Gavin, W. (2005). Inflation Targeting, Price Path Targeting and Indeterminacy. Economics Letters, 88(3), 336-342. https://doi.org/10.1016/j.econlet.2005.03.003

Fair R. C. (2008). Testing Price Equations. European Economic Review, 52(8), 1424-1437.

Farmer, R. E. A. (1999). Macroeconomics of Self-fulfilling Prophecies, $2^{\text {nd }}$ edition, MIT Press.

Froyen, R. T., \& Guender, A. V. (2007). Optimal Monetary Policy under Uncertainty. Cheltenham : E. Elgar. https://doi.org/10.4337/9781847208644

Gali, J. (2008). Monetary Policy, Inflation and the Business Cycle. Princeton: Princeton University Press.

Gerko, E., \& Sossounov, K. (2015). Trend Inflation and Monetary Policy Rules: Determinacy Analyses in a New Keynesian model with Capital Accumulation. The B.E. Journal of Macroeconomics, 15(1), 1-29. https://doi.org/10.1515/bejm-2012-0071

Giannoni, M. P. (2014). Optimal Interest-Rules in a Forward-Looking Model and Inflation Stabilization versus Price-Level Stabilization. Journal of Economic Dynamics and Control, 41(c), 110-129. https://doi.org/10.1016/j.jedc.2014.01.013

Guender, A. V. (2011). The Timeless Perspective vs Discretion: Monetary Policy Implications for an Open Economy. Journal of International Money and Finance, 30(8), 1638-1658. https://doi.org/10.1016/j.jimonfin.2011.09.001

Hirose, Y., Kurozumi, T. W., \& Van Zandweghe (2017). Monetary Policy and Macroeconomic Stability Revisited. Federal Reserve Bank of Kansas City, Research Working Paper, 17-01. https://doi.org/10.18651/RWP2017-01

Kiley, T. (2007). Is Moderate-to-High Inflation Inherently Unstable? International Journal of Central Banking, 3(2), 173-201.

Kilponen, J., Vilmunen, J., \& Oscari, V. (2013). Estimating Inter-temporal Elasticity of Substitution in a Sticky Price Model. Research Discussion Papers \#9, Bank of Finland. https://doi.org/10.2139/ssrn.2291392

Koenig, E. F., Leeson, F., \& Khan, G. A.(2012). The Taylor Rule and the Transformation of Monetary Policy. Stanford: The Hoover Institution Press.

LaSalle, J. P. (1986). The Stability and Control of Discrete Processes. Applied Mathematical Sciences, 62, Springer-Verlag. https://doi.org/10.1007/978-1-4612-1076-4

Lim, G. C., \& McNellis, P. D. (2008). Computational Macroeconomics for the Open Economy, The MIT Press.

Liu, F., \& Sercu, P. (2009). Estimating the Inter-temporal Substitution of Elasticity”, CiteSeerX Digital Library. https://doi.org/10.2139/ssrn.1344231

Lliosa, L. G., \& Tuesta, V. (2008). Determinacy and Learnability of Monetary Policy Rules in Small Open Economies. Journal of Money, Credit and Banking, 40(5), 1033-1063. https://doi.org/10.1111/j.1538-4616.2008.00145.x

Petursson T. G. (2002). Wage and Price Formation in a Small Open Economy: Evidence from Iceland”, Working Paper 16 , Bank of Iceland.

Richter, A. W., \& Throckmorton, N. A. (2016). Is Rotemberg Justified by Macro-data? Economics Letters, 149(C), 
44-48. https://doi.org/10.1016/j.econlet.2016.10.011

Robinson J. (1933). The Economics of Imperfect Competition. Macmillan, 281-291.

Rotemberg, J. J. (1982). Sticky Prices in the United States. Journal of Political Economy, 90(6), 1187-1211. https://doi.org/10.1086/261117

Taylor, J. B. (1993). Discretion versus Policy Rules in Practice. Carnegie Rochester Conference Series on Public Policy, 39, 195-214. https://doi.org/10.1016/0167-2231(93)90009-L

Williams, J. C. (1999).Simple Rules for Monetary Policy. Finance and Economics Discussion Series\#12. Board of Governors of the Federal Reserve System.

Woodford, M. (2003). Interest and Prices. Princeton: Princeton University Press.

\section{APPENDIX}

A.1

The inter-temporal utility function is given by:

$$
E_{t} \sum_{t=0}^{\infty} \beta^{t} U\left(\tilde{C}_{t}\right) e^{v_{t+i}}
$$

(a tilde denotes a real variable); $\beta$ is a discount rate; $v_{t}$ is a white noise stochastic term.

For our purposes, the one -period utility function is given by:

The budget constraint is:

$$
U\left[\tilde{C}_{t}\right]=\frac{\left[\tilde{C}_{t}^{1-1 / \rho}\right]}{1-1 / \rho} e^{v_{t}}=\frac{\left[\tilde{C}_{t}^{d}, \tilde{C}_{t}^{f}\right]^{1-1 / \rho}}{1-1 / \rho} e^{v_{t}}
$$

$\tilde{C}_{t+i}+\widetilde{B}_{t+i} / \widetilde{\Pi}_{t+i}=\left(1+R_{t-1+i}\right)\left(\widetilde{B}_{t-1+i} / \widetilde{\Pi}_{t+i}\right)$ +labor income, $i=0,1,2$

Applying the Lagrangian method with respect to $\widetilde{C}_{t}$ and $\widetilde{B}_{t}$, we derive:

$$
\begin{gathered}
e^{v_{t}}\left[\tilde{C}_{t}^{-1 / \rho}\right]=\tilde{\Lambda}_{t}\left(\text { A. 1.1) } \quad \tilde{\Lambda}_{t} / \widetilde{\Pi}_{t}=E_{t} \beta\left[\tilde{\Lambda}_{t+1} / \widetilde{\Pi}_{t+1}\right]\left(1+R_{t}\right)\right. \\
\tilde{\Lambda}_{t} \text { is the Lagrangian multiplier }
\end{gathered}
$$

These conditions yield, through combination, equation (3.1.3) in the text, after taking logs.

A.2: $C_{10}, C_{20}, C_{30}$ are given respectively by:

$$
\left[\begin{array}{ccc}
1 & \Phi_{1} \theta+\Phi_{2} & \Phi_{1}(1-\theta)-\Phi_{2} \\
0 & \alpha_{3} & 0 \\
0 & 1 & 1
\end{array}\right]\left[\begin{array}{ccc}
1+\Phi_{1} \Phi_{Y} & \Phi_{1} \Phi_{P}+\Phi_{1} \theta+\Phi_{2} & \Phi_{1}(1-\theta)-\Phi_{2} \\
-\alpha_{2} \gamma_{1} & 1 & -\alpha_{2} \gamma_{2} \\
\Phi_{Y} & \Phi_{P} & 1
\end{array}\right]\left[\begin{array}{ccc}
0 & 0 & 0 \\
0 & -\alpha_{1} & 0 \\
0 & 0 & 0
\end{array}\right]
$$

A.3: Although the focus of this paper is by far, the issue of determinacy, many studies on monetary policy rules deal with the question of optimization which we shall briefly address; let us specify the target volatility function:

$$
\operatorname{Min} E_{t} \sum_{0}^{\infty} \beta^{t}\left[\left(P_{t}-\bar{P}\right)^{2}+\varphi\left(Y_{t}-\bar{Y}\right)^{2}\right]
$$

We consider a stripped down version of the model consisting of equations 3.1.1 $\alpha, 3.3 .1,3.4 .1$, describing an economy of pure exchange reminiscent of the basic version of De Fiore and Liu (op.cit.). Unlike the closed economy, the optimal values of $\Phi_{P}^{*}$ and $\Phi_{r}^{*}$ in a Taylor rule with a PLT component may be shown to have a key characteristic feature, namely that both depend explicitly on the degree of openness of the trade sector.

\section{Copyrights}

Copyright for this article is retained by the author(s), with first publication rights granted to the journal.

This is an open-access article distributed under the terms and conditions of the Creative Commons Attribution license which permits unrestricted use, distribution, and reproduction in any medium, provided the original work is properly cited. 